\title{
ADHAAR: A RELIABLE DATA HIDING TECHNIQUES WITH (NNP2) ALGORITHMIC APPROACH USING X-RAY IMAGES
}

R. Karthick

Assistant Professor, Electronics and Communication Engineering, Sethu Institute of Technology,

Virudhunagar, Tamil Nadu, (India).

E-mail: karthickkiwi@gmail.com

ORCID: https://orcid.org/0000-0002-3222-0185

Meenalochini Pandi

Assistant Professor, Electrical and Electronics Engineering, Sethu Institute of Technology,

Virudhunagar, Tamil Nadu, (India).

E-mail: meenalochinip@gmail.com

ORCID: https://orcid.org/0000-0003-3601-4773

M. Sheik Dawood

Professor, Electronics and Communication Engineering, Sethu Institute of Technology,

Virudhunagar, Tamil Nadu, (India).

E-mail: sheikdawood7@gmail.com

ORCID: https://orcid.org/0000-0002-8767-386X

A. Manoj Prabaharan

Assistant Professor, Electronics and Communication Engineering, Sethu Institute of Technology,

Virudhunagar, Tamil Nadu, (India).

E-mail: manojprabaharann@gmail.com

ORCID: https://orcid.org/0000-0003-0055-716X

P. Selvaprasanth

Assistant Professor, Electronics and Communication Engineering, Sethu Institute of Technology,

Virudhunagar, Tamil Nadu, (India).

E-mail: selvaprasanth9619@gmail.com

ORCID: https://orcid.org/0000-0003-3491-1243

Recepción: 29/11/2019 Aceptación: 05/03/2021 Publicación: 30/11/2021

\section{Citación sugerida:}

Karthick, R., Pandi, M., Dawood, M. S., Prabaharan, A., M., y Selvaprasanth, P. (2021). ADHAAR: A reliable Data Hiding techniques with (NNP2) Algorithmic Approach using X-ray images. 3C Tecnología. Glosas de innovación aplicadas a la pyme, Edición Especial, (noviembre, 2021), 597-609. https:// doi.org/10.17993/3ctecno.2021.specialissue8.597-609 


\section{ABSTRACT}

The technique which is most important for the Reversible Data Hiding $(\mathrm{RDH})$ is Prediction Error Expansion (PEE) through this we can hide large messages into digital media with little distortion. The Nearest Neighborhood Pixel Prediction (NNP2) algorithm which goes under the process of the Rhombus prediction and Chinese Remainder Theorem (CRT). In which these several methods are used for the prediction errors, variation of prediction and pixel are used to embed data. The combined Chinese Remainder Theorem as well as Rhombus prediction provides better quality output rather than traditional one. For embedding several bits into one embeddable pixel the size have to be modified and adjusted using Chinese Remainder Theorem (CRT). The distortion level is reduced by Histogram Shifting (HS). The performance of proposed method is evaluated using PSNR for number of medical images. The simulation results provide the best encoded capacity as well as good image pattern than ancient techniques.

\section{KEYWORDS}

Prediction Error Expansion (PEE), Difference Expansion (DE), Histogram Shifting (HS). 


\section{INTRODUCTION}

The renowned technique called Reversible data hiding $(\mathrm{RDH})$ gives reversibility solution for some sensitive media i.e., satellite images and medical images were taken into account for calculating lossless embedded data (El Bey et al., 2016). The output data can be totally recovered by means of adapting embed data into media, mostly hidden data are achieved from Reversible data hiding $(\mathrm{RDH})$ techniques. Based on all the studies there provides an existing method (Pande \& Varshney, 2017) i.e. DWT Discrete Wavelet Transform. This method provides the same process of Reversible Data Hiding RDH with low accuracy, higher distortion and security less, low data hiding capacity (Ayyappan \& Lakshmi, 2018). To overcome all the drawbacks, we have overcome with new method based on NNP2 algorithm and Rhombus prediction (Karthick et al., 2019).

In Suseela, Lakshmi and Jyothy (2017) has provided a useful study on A Novel approach for digital image watermarking. The parameters and algorithm which uses in many techniques is guided by Tiwari and Sardar (2017) and Tiwari and Sharmila (2017) by the Digital Watermarking applications, Parameter Measures and techniques. In Shreekumar and Salam (2014) provided the information for embedding as a medical information using minimization of scaling factor from Firely algorithm. To optimize bottom level of image distortion moves to combined histogram shifting and reversible data hiding techniques (Karthick \& Sundararajan, 2017a, 2017b, 2017c, 2018). By means of identifying peak values and zero values proposed RDH based histogram shifting is implemented for lower image distortion. Here, we have proposed Chinese remainder algorithm based NNP2 rhombus prediction techniques. The remaining sections are partitioned into ADHAAR methodology and experimental results.

\section{ADHAAR METHODOLOGY}

ADHAAR methodology section shows brief information about Chinese remainder theorem. The proposed techniques are given below. 


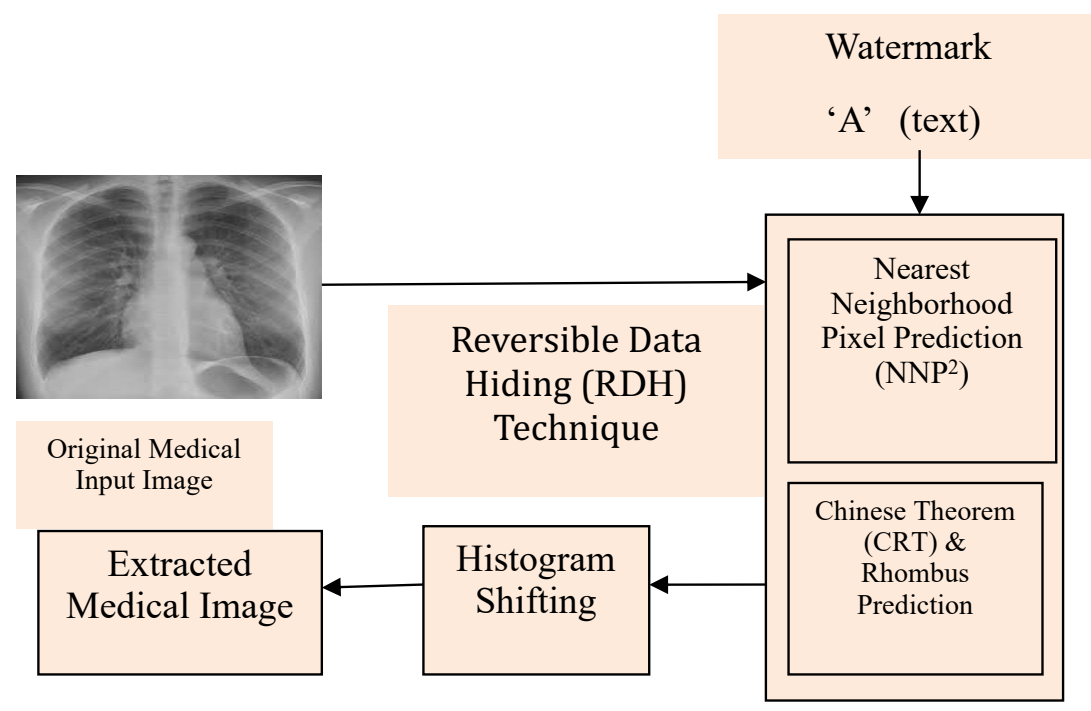

Figure 1. Proposed nearest neighborhood pixel prediction (NNP2) Algorithm.

Source: own elaboration.

\subsection{CHINESE REMAINDER THEOREM}

The basic concept of CRT shows that a congruence system. A well-known mod set $\{\mathrm{n} 1$, $n 2, \ldots . n m\}$ where $m$ is a positive integer, and $\operatorname{GCD}\left(n_{i}, n_{j}\right)=1$ for i not equal to $j, i, j \in[0, m]$ (Kaur \& Shukla, 2014). For a positive integer $\mathrm{X}$, there exist equation $\mathrm{xi}=\mathrm{X} \bmod$ ni, where $\mathrm{i}=1,2, \ldots \mathrm{m}$. The $\mathrm{m}$-tuple $\mathrm{x} 1, \mathrm{x} 2, \ldots . \mathrm{xm}$ is isolated for all $\mathrm{X} €\{0, \mathbb{I} \mathbb{n} \mathrm{ni}\}$. The description of CRT is given:

$$
\begin{gathered}
N=\prod_{i=1}^{m} n_{i} N_{i}=N / n_{i} \\
a_{i}=N_{i}^{-1} \bmod N \\
C=\left(\sum_{i=1}^{m} x_{i} * n_{i} * a_{i}\right) \bmod N
\end{gathered}
$$

These equations describe the isolated solution for CRT theorem, where $\mathrm{C}$ in this equation manages the m-tuple $\left\{\mathrm{x}_{1}, \mathrm{x}_{2}, \ldots \ldots \ldots \ldots \mathrm{x}_{\mathrm{m}}\right\}$

\subsection{NNP2 WITH RHOMBUS PREDICTION}

In NNP2 provides the rhombus prediction to exhibits the nearly neighboring pixels with largest correlation. 


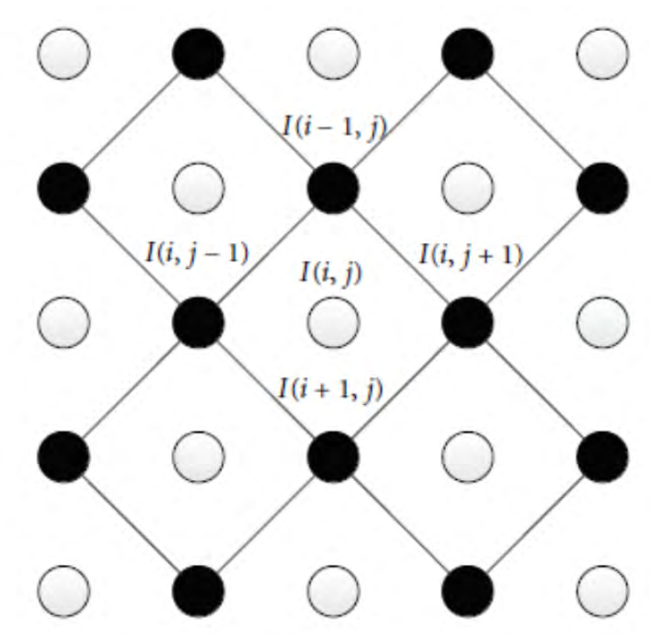

Figure 2. Rhombus prediction.

Source: own elaboration.

The pixel can be predicted by $\mathrm{p}_{\mathrm{i}, \mathrm{j}}$, rhombus prediction considers 4 nearer pixels, $\mathrm{P}_{\mathrm{i}-1}, \mathrm{j}, \mathrm{P}_{\mathrm{i}}$, ${ }_{j+1}, P_{i}, j-1, P_{i+1}, j$. The central pixel $p_{i, j}$, achieved by right, left, upper and bottom pixels, $\mathrm{P}_{\mathrm{i}, \mathrm{j}-1}, \mathrm{P}_{\mathrm{i}-1, j}, \mathrm{P}_{\mathrm{i}, j+1}, \mathrm{P}_{\mathrm{i}+1, j}$. There are two prime values taken into account for encoding the white pixels called data embedding algorithm.

$$
\mathrm{N}=\log _{2}(\mathrm{q})
$$

The threshold values, $\mathrm{T}=(\mathrm{q}-1) * \mathrm{p}$

Step (i): calculation of prediction value

The prediction $\mathrm{P}_{\mathrm{i}, \mathrm{j}}$ is calculated by the equation,

$$
p_{i, j}=\frac{\left\lfloor I_{i, j-1}+I_{i-1, j}+I_{i, j+1}+I_{i+1, j}\right\rfloor}{4}
$$

$P_{i}, j$ is the predicted value of pixel.

Step (ii): calculation of absolute value.

The absolute value is the difference between original and predicted value of pixels $\mathrm{D}=\mid \mathrm{I}_{\mathrm{i}}, \mathrm{j}$

$-\mathrm{p}_{\mathrm{i}, \mathrm{j}} \mid$

Where, 
$I_{i, j}$ is a value of original pixels

$\mathrm{D}$ is a difference between original and predicted value of pixels.

Step (iii): calculation using CRT.

To calculate the integer $\mathrm{C}$ using Chinese remainder theorem, read $\mathrm{N}$ bits from secret file (binary data), and its decimal value is $\mathrm{x}$.

$$
C=\left(\sum_{i=1}^{m} x i * N 1 * a i\right) \bmod N
$$

Where,

$$
\begin{gathered}
N=\prod_{i=1}^{m} n_{i} \\
N_{i}=N / n_{i} \\
a_{i}=N_{i}^{-1} \bmod N
\end{gathered}
$$

Step (iv): Embedding stage: The calculated value of $\mathrm{C}$ will be embedded into the original value of pixels. The watermarked pixel value is given by,

If $\mathrm{O} \leq \mathrm{D}<\mathrm{p}$

$$
w_{i, j}=\left\{\begin{array}{l}
p_{i, j}+C, I_{i, j} \geq p_{i, j} \\
p_{i, j}-C, I_{i, j}<p_{i, j}
\end{array}\right.
$$

Hence,

$\mathrm{W}_{\mathrm{i}, \mathrm{j}}$ is the pixel(watermarked) value of $\mathrm{I}_{\mathrm{i}, \mathrm{j}}$

If $\mathrm{D} \geq \mathrm{p}$,

$$
w_{i, j}=\left\{\begin{array}{l}
p_{i, j}+T, I_{i, j} \geq p_{i, j} \\
p_{i, j}-T, I_{i, j}<p_{i, j}
\end{array}\right.
$$

whereas,

$\mathrm{W}_{\mathrm{i}, \mathrm{j}}$ is the pixel (watermarked) value of $\mathrm{I}_{\mathrm{i}, \mathrm{j}}$ 
$\mathrm{T}$ is threshold.

The "black pixels" are remains constant and watermarking is adopted for "white pixels" are shows the prediction value using embedding algorithm.

\subsection{HISTOGRAM SHIFTING}

Each and every variable intensity the number pixels showing an image in histogram graph. The output image of RDH technique is subjected to histogram shifting to reduce the distortion level. The secret bits are embedded with the prime values $\mathrm{p}$ and $\mathrm{q}$.

However to prevent overflow and underflow the histogram is shifted. The histogram of extracted image is shifted to $\mathrm{L}=\mathrm{p} \times \mathrm{q}$ - $\mathrm{p}$ units. By using above condition, while $\mathrm{p}$ and $\mathrm{q}$, are an integer, the value of $q$ is set as multiples of 2, such as $2 \mathrm{n}$ pixel can be embed 6 bits at most.

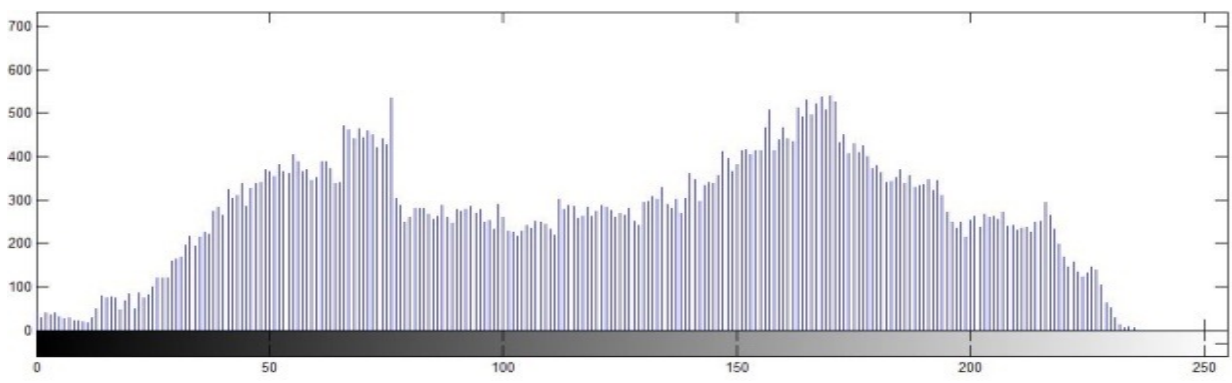

Figure 3. Histogram of extracted image.

Source: own elaboration.

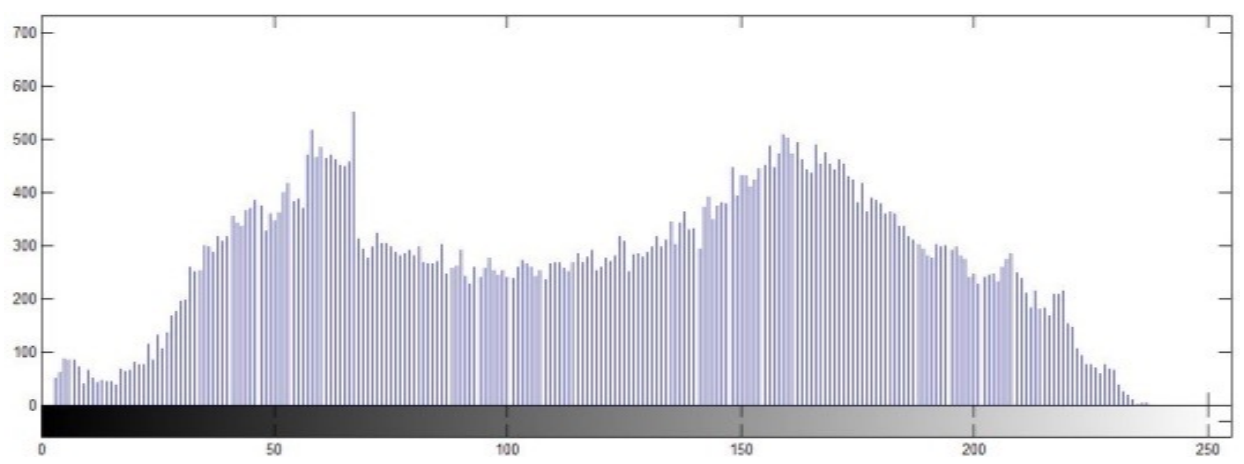

Figure 4. Histogram after shifting.

Source: own elaboration. 


\section{RESULTS AND DISCUSSION}

PSNR is computed between the two medical images. The original image and extracted image from watermarking used measure the quality. The better quality attained from higher value of PSNR with reconstructed or extracted image. The image quality can be achieved by the known metrics MSE and PSNR. The PSNR gives the measurement of peak error and MSE gives the ratio between the reconstructed image and original image. The error can be minimized by means of optimize the MSE value.

The formula for PSNR is given in the Equation respectively.

$$
P S N R=10 \log _{10}\left(\frac{R^{2}}{M S E}\right)
$$

$\mathrm{R}$ is max fluctuations in an input image data.

The acquired medical images are shown in:

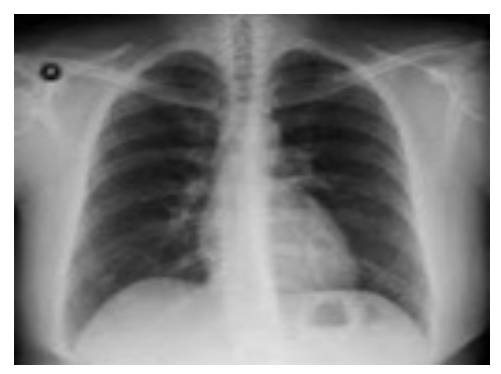

Figure 5.1. Sample input image 1.

Source: own elaboration.

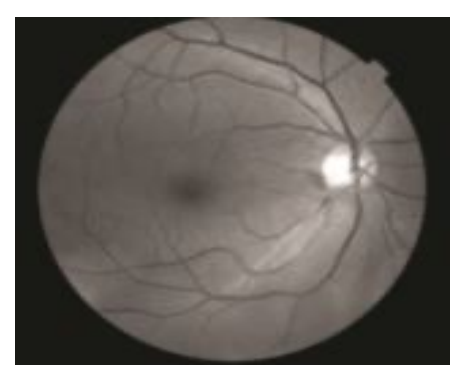

Figure 5.2. Sample input image 2 .

Source: own elaboration. 


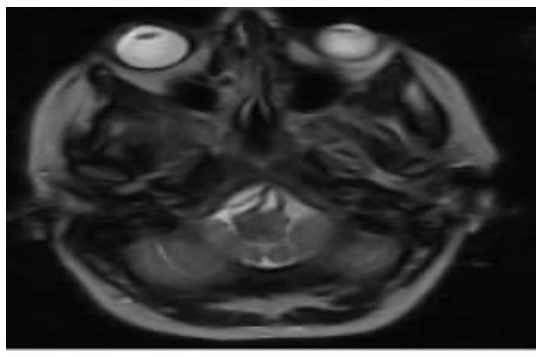

Figure 5.3. Sample input image 3.

Source: own elaboration.

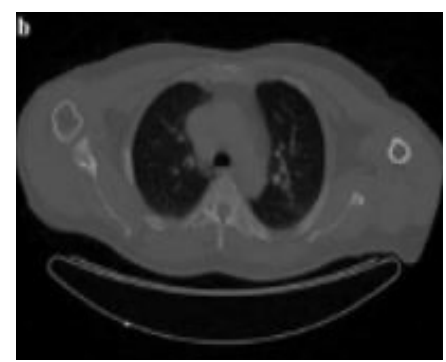

Figure 5.4. Sample input image 4.

Source: own elaboration.

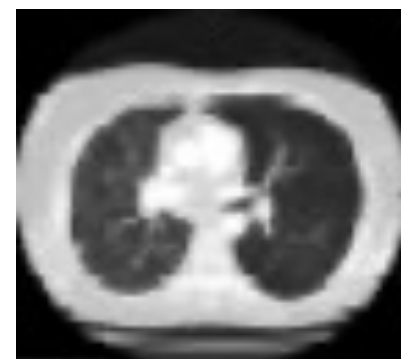

Figure 5.5. Sample input image 5.

Source: own elaboration.

Table 1. Calculation of PSNR reading.

\begin{tabular}{|c|c|c|}
\hline INPUT IMAGE & DWT & $\begin{array}{c}\text { RHOMBUS } \\
\text { PREDICTION }\end{array}$ \\
\hline Sample input 1 & 6.59 & 38.02 \\
\hline Sample input 2 & 10.23 & 37.49 \\
\hline Sample input 3 & 22.16 & 39.18 \\
\hline Sample input 4 & 26.83 & 41 \\
\hline Sample input 5 & 31.21 & 41.49 \\
\hline
\end{tabular}

Source: own elaboration. 
PSNR value graphical representation for the existing and the proposed method.

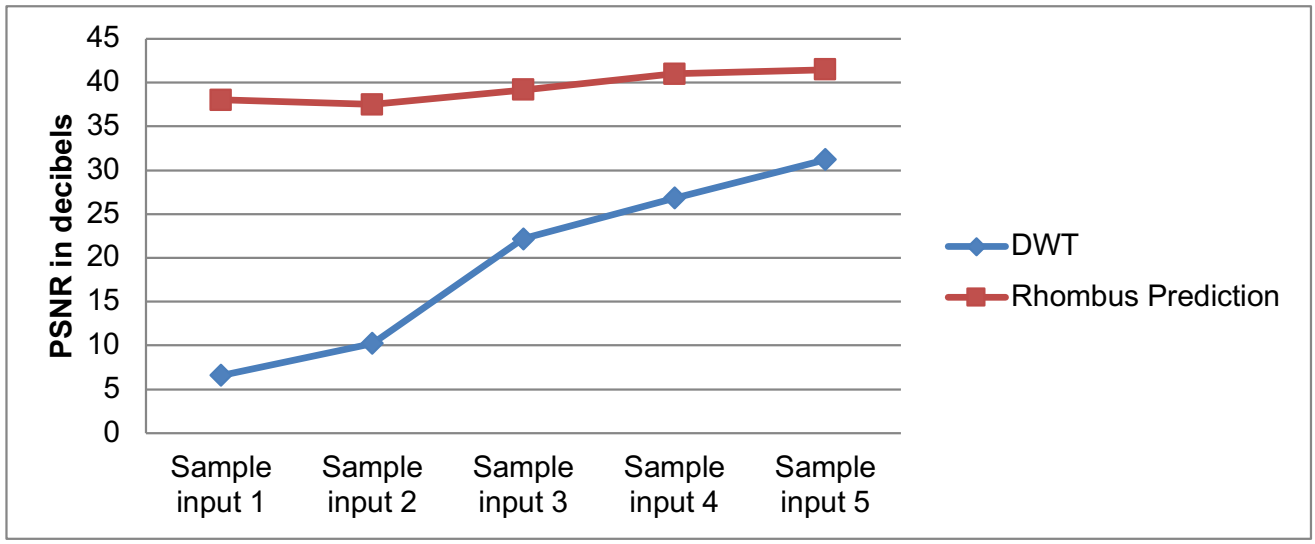

Figure 6. Sample tested Image DWT vs Rhombus prediction.

Source: own elaboration.

\section{CONCLUSIONS}

In this work, secured medical image transmission is proposed using image processing techniques. Medical images are taken as original images. Watermark is embedded into original image to be transmitted by using NNP2 algorithm. Clearly the proposed NNP2 with rhombus prediction provides lower distortion with larger embedding capacity than conventional method. As a result, the graphical representation of DWT Vs rhombus prediction (NNP2) achieved good performance in reversible data hiding schemes.in addition; we use histogram shifting to prevent distortion.

\section{ACKNOWLEDGEMENT}

I would like to thank Professor Dr. M. Sundararajan for his expert advice and encouragement throughout this research work.

\section{REFERENCES}

Ayyappan, S., \& Lakshmi, C. (2018). A Review on Reversible Data Hiding Techniques. International Fournal of Applied Engineering Research, 13(5), 2857-2864. https://www. ripublication.com/ijaer18/ijaerv13n5_102.pdf 
El Bey, A. A., Saleem, A., Abed-Meraim, K., \& Beghdadi, A. (2016). Watermark extraction Using Blind Image separation and Sparse Representation. In 5th International Workshop on Signal Processing and its Applications. https://hal.archivesouvertes.fr/hal-01770985/document

Karthick, R., \& Sathiyanathan, N. (2018). Medical Image Compression Using View Compensated Wavelet Transform. Journal of Global Research in Computer Science 9(9), 11-15. https://www.researchgate.net/publication/328118446_MEDICAL_ IMAGE_COMPRESSION_USING_VIEW_COMPENSATED_WAVELET_ TRANSFORM

Karthick, R., \& Sundararajan, M. (2017a). A Reconfigurable Method for Time Correlated MIMO Channels with a Decision Feedback Receiver. International fournal of Applied Engineering Research, 12(15), 5234-5241. https://www.ripublication.com/ ijaer17/ijaerv12n15_\%20(73).pdf

Karthick, R., \& Sundararajan, M. (2017b). PSO based out-of-order (OoO) execution scheme for HT-MPSOC. Fournal of Advanced Research in Dynamical and Control Systems, 9(6), 1969-1986. https://www.researchgate.net/publication/320134442_PSO_ based_out-of-order_OoO_execution_scheme_forht-MPSOC

Karthick, R., \& Sundararajan, M. (2017c). Design and Implementation of Low Power Testing Using Advanced Razor Based Processor. International Fournal of Applied Engineering Research, 12(17), 6384-6390. https://www.ripublication.com/ijaer17/ ijaerv12n17_09.pdf

Karthick, R., \& Sundararajan, M. (2018). A novel 3-D-IC test architecture-a review. International Fournal of Engineering and Technology (UAE), 7(1.1). https://www. sciencepubco.com/index.php/ijet/article/view/10228

Karthick, R., Prabaharan, A. M., Selvaprasanth, P., Sathiyanathan, N., \& Nagaraj, A. (2019), High Resolution Image Scaling Using Fuzzy Based FPGA Implementation. Asian Fournal of Applied Science and Technology (AJAST), 3(1), 215-221. https://ssrn.com/abstract=3353627 
Kaur, S., \& Shukla, M. (2014). Reversible Data Hiding and its Methods: a survey. International journal of Computer Science and Mobile Computing, 3(5), 821-826. https:// ijcsmc.com/docs/papers/May2014/V3I5201499a60.pdf

Konduru, U.P., \& Nagarajan, A.P. (2018). A Review of Reversible Data Hiding Technique Based on Steganography. Asian Research Publishing Network, 13(3), 1105-1114. https:// www.researchgate.net/publication/323470424_A_REVIEW_OF_REVERSIBLE_ DATA_HIDING_TEGHNIQUE_BASED_ON_STEGANOGRAPHY

Pande, S., \& Varshney, S. (2017). Hybrid Technique based Blind Digital Image Watermarking. International journal of Engineering and Computer Science, 6, 19936-19940. https://www.semanticscholar.org/paper/Hybrid-Technique-Based-Blind-DigitalImage-Pande/03a7ale5288c66f2d01d738762cde1b1cc1d9cc9

Shreekumar, S., \& Salam, V. (2014). Advanced Reversible Data Hiding with Encrypted Data. International journal of Engineering Trends and technology, 13(7). http://www. ijettjournal.org/archive/ijett-v13p262

Suseela, D. V. L., Lakshmi, O., \& Jyothy, A. (2017). A Novel approach for Digital Image watermarking. Corpus ID: 45115119. https://www.semanticscholar.org/paper/1-ANOVEL-APPROACH-FOR-DIGITAL-IMAGE-WATERMARKING-Suseela-La kshmi/51552658e1340c4ad51c07570b7e60f9a8a01c4c

Tiwari, N., \& Sardar, A. S. (2017). Advancement in Reversible Data Hiding techniques. International journal of Computer Science and Network Security, 17(3). http://paper.ijcsns. org/07_book/201703/20170323.pdf

Tiwari, N., \& Sharmila. (2017). Digital watermarking applications, Parameter Measures and techniques. International journal of Computer Science and Network Security, 17(3). http:/ / paper.ijcsns.org/07_book/201703/20170322.pdf 
